\title{
Importance of Gelatinization Degree of Starch Paste Binder in Hardness and Disintegration Time of Tablets
}

\author{
Tadashi Makino* and Nobuyuki Kitamori \\ Pharmaceutical Development Laboratories, Production Division, Takeda Chemical Ind., Ltd., 2-17-85, Juso-honmachi, \\ Yodogawa-ku, Osaka 532, Japan. Received August 22, 1994; accepted November 21, 1994
}

Lactose and ascorbic acid powders were granulated using corn or potato starch pastes. Starch pastes were cooked at different temperatures to obtain pastes of different degrees of gelatinization. The granules obtained were compressed into tablets and the hardness and disintegration time were examined. The gelatinization degree of starch paste was found to be closely related to the tablet properties, especially its disintegration time. An increase in gelatinization degree of the paste prolonged the disintegration time of the resultant tablets, although tablet hardness did not change. The relation between the gelatinization degree of starch paste and tablet properties is discussed.

Key words starch paste; gelatinization degree; tablet hardness; disintegration time

Although starch paste has long been used as a binder for making granules for tablets in the pharmaceutical industry, little information is available on the effect of this paste on properties of the tablets. Only the effects of the viscosity or thickness of the paste ${ }^{1,2)}$ and massing time or intensity ${ }^{2,3)}$ on the properties of granules and tablets have been reported. These studies, however, dealt with the effect of the distribution of paste in the granules on tablet properties. In the wet granulation process, uniform binder distribution is desirable for the binder used to exhibit its full binding capacity. Starch paste prepared under various cooking conditions should be evaluated in strictly controlled experiments.

Some useful artificial binding materials have recently appeared on the market; however, starch paste is still one of the most useful binders because of its good compatibility with drugs. For example, ascorbic acid is very sensitive to many binders but is not to starch paste. ${ }^{4)}$ In many cases, the conditions for the preparation of starch paste are not documented, and conditions for the preparation of paste overall do not seem to be well controlled.

As another aspect of the starch paste, the content of amylose and amylopectin in natural starch and its effect on hardness and disintegration time of tablets was reported. ${ }^{5)}$

The object of this paper is to demonstrate the effect of cooking temperature of starch paste on the properties of the resulting tablets.

\section{Experimental}

Materials Lactose powder (200 mesh, D. M. V., Holland) and ascorbic acid powder (Takeda Chemical Ind., Ltd.) were used in tablet formulations. Experience has shown us that these powders are easily affected by starch paste and alter the properties of the resultant tablets. Corn (Nippon Cornstarch Co., Ltd.) and potato starches (Nippon Starch Chemical Co., Ltd.) were used for making the paste.

Preparation of Starch Paste Starch suspension in distilled water was heated in a water bath (BT-21, Yamato) under continuous gentle agitation for about $30 \mathrm{~min}$ at various temperatures. Concentrations of starch suspensions were $10 \%(\mathrm{w} / \mathrm{w})$ for lactose granulation and $5 \%(\mathrm{w} / \mathrm{w})$ for ascorbic acid granulation.

Tablet Preparation Two simple tablet formulas for lactose and ascorbic acid tablets were chosen to determine the effect of starch paste on the tablet properties.

Unless otherwise stated, starch paste was used at $3 \%$ on a dry weight basis of the final granules for both lactose and ascorbic acid granules.
Lactose powder was massed with starch paste $\left(50-90^{\circ} \mathrm{C}\right)$ in a mortar to achieve a uniform distribution of the binding material, passed through a 32-mesh sieve, dried in a vacuum dryer at $40^{\circ} \mathrm{C}$ for $16 \mathrm{~h}$, and then again passed through a 32-mesh sieve. For ascorbic acid powder, granulation was carried out on a fluidized-bed granulator (Inlet air temp. $90{ }^{\circ} \mathrm{C}$, paste temp.: $50-90^{\circ} \mathrm{C}$ ) (WSG-15, Glatt-Okawara) spraying starch paste. The granules were then passed through a cutter mill (Power Mill Type P-3, Showa Kagaku).

Four hundred milligrams of granules without a lubricant were compressed on a physical testing instrument (Autograph IS-5000, Shimadzu) to make flat-faced tablets using a $10 \mathrm{~mm}$ diameter punch and die. The die wall and punch surface were dusted with magnesium stearate powder prior to each compression. Tablets were compressed at $1.5 \mathrm{t} / \mathrm{cm}^{2}$ and at a constant strain rate of $5 \mathrm{~mm} / \mathrm{min}$.

Evaluation Viscosity and degree of gelatinization of starch were examined to characterize the pastes. Viscosity was measured by a Brabender amylograph (Brabender); a Brookfield type viscometer (Tokyo Kasei), and degree of gelatinization was measured by the Mikumo method. ${ }^{6)}$

Hardness of tablets was measured by a diametral compression test on a hardness tester (TH-204K, Toyama). Measurements are expressed in terms of mean of 10 tablets.

Disintegration time was determined in water at $37^{\circ} \mathrm{C}$ according to the JP XII method without discs.

\section{Results}

Characterization of Starch Paste The Brabender amylograms for two starches are shown in Fig. 1. It is clear that different starches start to gelatinize at different temperatures: cornstarch at approximately $75^{\circ} \mathrm{C}$ and

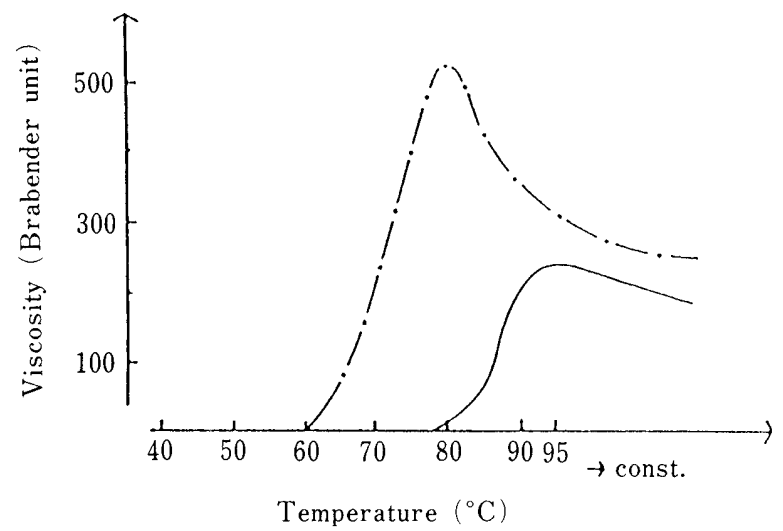

Fig. 1. A Brabender Amylogram for Corn and Potato Starch Suspensions

Heating rate; $15^{\circ} \mathrm{C} / \mathrm{min}$, concentration; $6 \%(\mathrm{w} / \mathrm{w})$. Key: -__, cornstrach; - - - , potato starch.

(C) 1995 Pharmaceutical Society of Japan 
potato starch at about $60^{\circ} \mathrm{C}$. These results almost agree the figures in a review article by Chalmers. ${ }^{7)}$

Maximum viscosity levels were also different between these starches.

Cooking Temperature of Starch Paste and Tablet Prop-
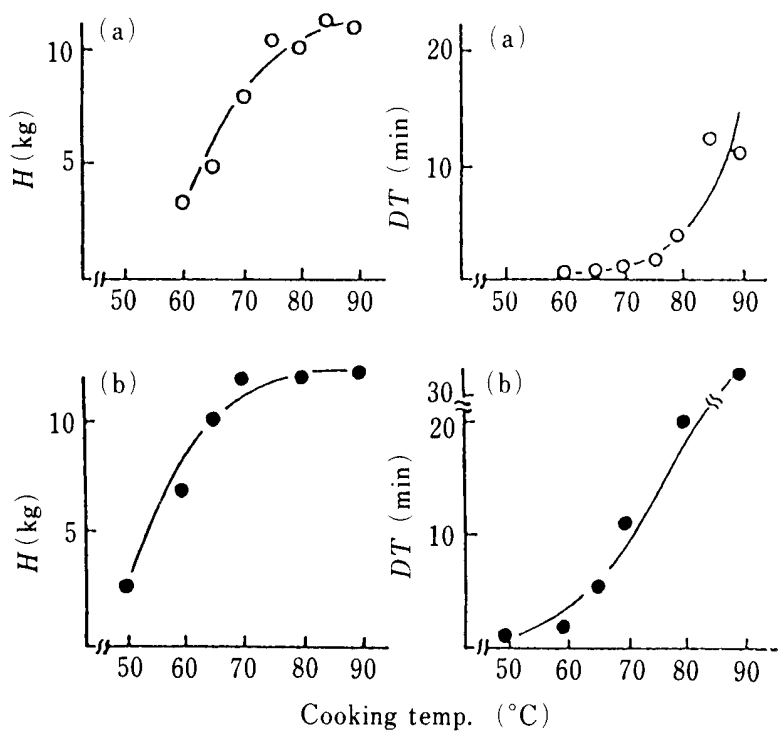

Fig. 2. Effect of Cooking Temperature of Starch Paste on the Properties of the Resulting Lactose Tablets

(a): cornstarch $3 \%$ (b): potato starch $3 \%$. erties Granules were prepared by massing powders with starch paste, then cooked at different temperatures and compressed into tablets. The relationship between the properties of the tablets and the cooking temperatures is shown in Fig. 2. The figure shows that the patterns for two lactose tablets prepared from granules with corn and potato starches, respectively, are the same. However, the temperatures at which the disintegration time began to change drastically differed between these two starches.

The hardness of tablets $(H)$ linearly increased up to a certain cooking temperature of the starch paste used to prepare the granules, and reached a certain constant value. Disintegration time $(D T)$ was very rapid up to the temperature just below that at which hardness reached a plateau, and then was prolonged as the temperature rose.

Gelatinization Degree and Tablet Properties Microscopic views of starch suspension at different stages of gelatinization are shown in Fig. 4: (A) initial state (before cooking), (B) starch paste at $78^{\circ} \mathrm{C}$, where starch grains are greatly swollen, (C) starch paste at $90^{\circ} \mathrm{C}$, where granular starches are no longer distinguishable.

Plots of the properties of lactose tablets prepared from granules with cornstarch pastes against gelatinization degree instead of cooking temperature of starch paste are shown in Fig. 5. The change in hardness of tablets against the gelatinization degree of starch is almost linear as shown.
(A)

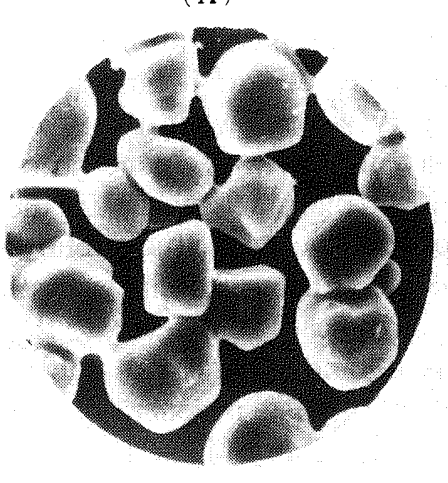

(B)

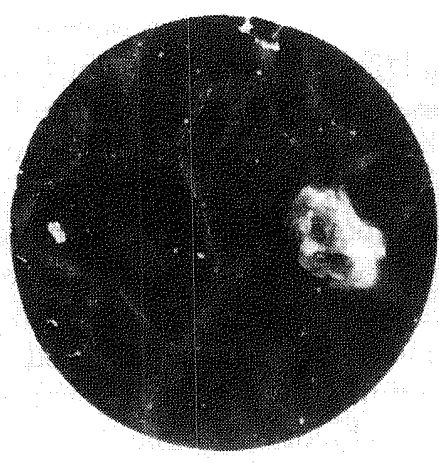

(C)

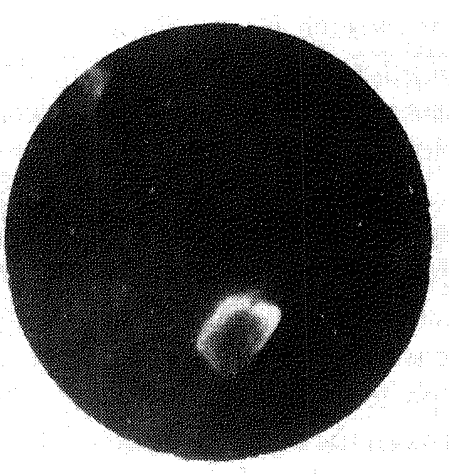

Fig. 3. Microscopic Views of Cornstarch Particles at Different Stages of Gelatinization

(A) raw materials, (B) at $78^{\circ} \mathrm{C},(\mathrm{C})$ at $90^{\circ} \mathrm{C}$.

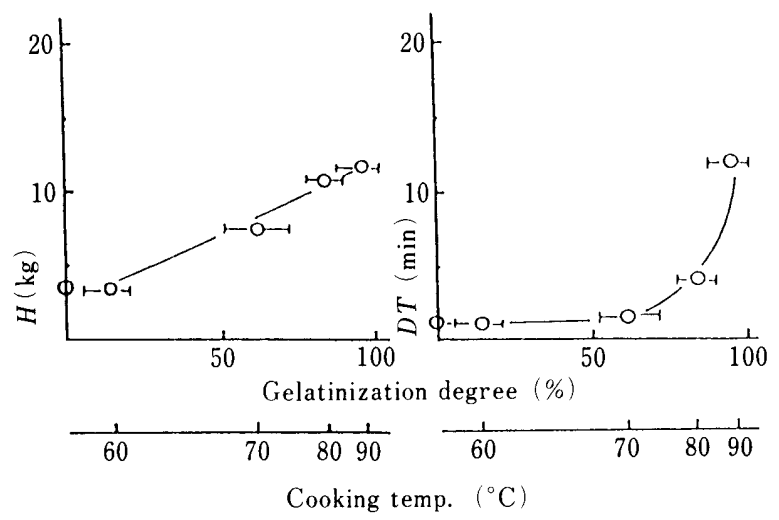

Fig. 4. Relationship between Cooking Temperature or Gelatinization Degree and Properties of the Resulting Lactose Tablets

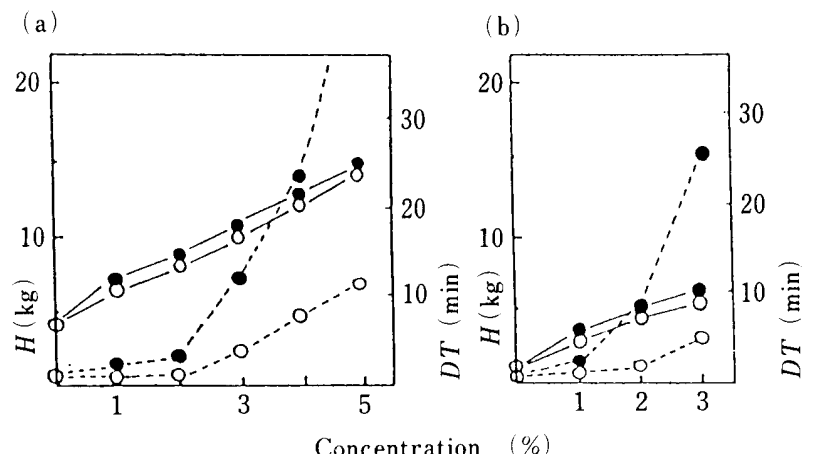

Fig. 5. Effect of Concentration of Binder on Properties of the Resulting Tablets

(a): lactose tablets, (b): ascorbic acid tablets. Key: $\mathrm{O}$. cooked at 78 "C;, cooked at $90 \mathrm{C}$; - , hardness; -....-., disintegration time. 
Concentration of Starch Binder in the Tablets and Tablet

Properties The effect of the concentration of starch binder incorporated in the tablet on tablet properties is shown in Fig. 5. Tablets from granules using starch binder were cooked at two different temperatures, e.g., at $78^{\circ} \mathrm{C}$, which is slightly above the gelatinization temperature of cornstarch, and at $90^{\circ} \mathrm{C}$, which is considerable above the gelatinization temperature. As the concentration of binder increased, tablet hardness increased almost linearly at both temperature levels, while disintegration time was prolonged in very different ways depending on the cooking temperature.

The same phenomenon was observed with ascorbic acid tablets (Fig. 5b).

\section{Discussion}

Figure 1 shows that each starch begins to gelatinize at a different temperature, for example, potato starch at about $60^{\circ} \mathrm{C}$ and cornstarch at about $75^{\circ} \mathrm{C}$. For any given starch, within the range of temperature used in normal preparation processes of the starch paste, cooking temperature has a great influence on tablet properties, especially disintegration time. This may be the reason for the inconsistent statements in some literature. For example, Remington says "starch paste which is useful as a binding agents will not generally be effective as a disintegration agents." ${ }^{\text {8) }}$ On the other hand, the statement "starch paste is a versatile binder, yielding granules and tablets which disintegrate readily." is seen in the book "Pharmaceutical Dosage Form: Tablets."9)

It would be of interest to discuss in more detail the effect of the starch paste properties on tablet properties, hardness and disintegration time.

It can easily be assumed that the hardness of tablets depends on the gelatinization degree, or on the proportion of gelatinized parts(amylopectin) of the binder used. As the cooking temperature increases, the gelatinization degree will increase and the proportion of gelatinized parts in the starch paste will also increase. Therefore, the relationship between the concentration of the starch binder and hardness shown in Fig. 5 must be very similar to that between gelatinization degree and tablet hardness shown in Fig. 4. In fact, the hardness of the tablets prepared from the granules using 3 percent of 50 percent gelatinized starch paste was about $7 \mathrm{~kg}$ (Fig. 4a), while the hardness of those prepared from granules using 1.5 percent of completely gelatinized starch paste was about $8 \mathrm{~kg}$ (Fig. 5a). These two values are very close.

In the disintegration time profile shown in Fig. 4 at the lower gelatinization degree, a tablet disintegrates rapidly with the dispersion of granules, while at a higher degree of gelatinization, the tablet disintegration is more like an erosion and disintegration takes longer. Figure 1 shows that the viscosity becomes very high at high gelatinization temperatures. This means that the viscosity of starch paste

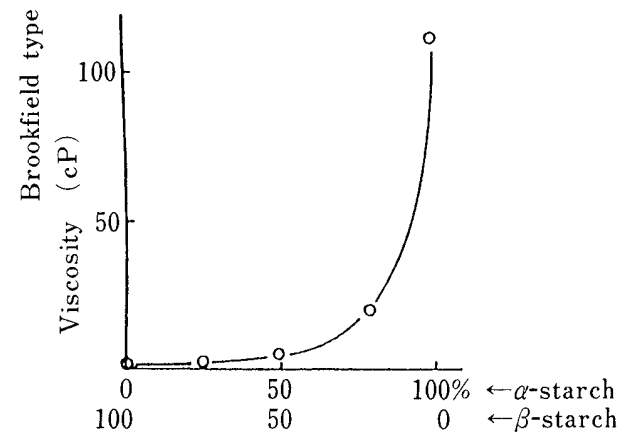

Fig. 6. The Viscosities of 5\% Aqueous Starch Suspensions Having Different Ratios of $\alpha$ - and $\beta$-Starch

increases with an increase in the content of gel in the suspension. A mixture of powdered pregelatinized starch $(\alpha$-starch), which easily forms gel in water, and grain starch ( $\beta$-starch) at varying ratios was suspended in water and the viscosities were measure. The viscosity of the suspension sharply increases with more than $60 \%$ of gel content as shown in Fig. 6. The profile coincides with that for the relationship between disintegration time and gelatinization degree, and, therefore, presumably to the prolongation of disintegration time for tablets.

The granules using the starch paste prepared just below the gelatinization point included starch grains in the binder layers. These swellable starch grains can enhance the separation of particles from the tablet surface. In contrast, disintegration time is extremely long with the tablets using starch binder prepared above the gelatinization point. Thus, the layer of starch binder on each particle may become highly viscous when the tablet is immersed in water and may prevent water penetration.

Internal addition of intact starch in the formulation would then be effective to reduce retardation of disintegration time when using starch paste. Such formulation is not always applicable, however, so that when starch paste is used as a binding agent in the formulation, a careful preparation of paste is generally required in order to maintain uniform quality of the tablet products.

\section{References}

1) P. M. Hill, J. Pharm. Sci., 65, 313 (1976).

2) Z. T. Chowhan, L. Palagyi, J. Pharm. Sci., 65, 1559 (1976).

3) T. Tiamjraj, D. Dingwall, Manuf. Chem. Aerosol News, 49, 43 (1978).

4) N. Kitamori, T. Makino, K. Hemmi, Manuf. Chem. Aerosol News, 50, 54 (1979).

5) J. B. Schwartz, J. A. Zelinskie, Drug Develop. Ind. Pharm., 4, 463 (1978).

6) R. Mikumo, Jpn. J. Toxicol. Environ. Health, 2, 18(1954).

7) L. Chalmers, Manuf. Chem. Aerosol News, 39, 23 (1968).

8) Remington's Pharmaceutical Science 16th ed., Mack Publishing Company, Easton, Pennsylvania, 1980, p. 1556.

9) H. A. Lieberman, L. Lachman (ed.), "Pharmaceutical Dosage Forms: Tablets," vol. 1, Marcel Dekker, Inc., New York \& Basel, 1980 , p. 123. 